\title{
Design of activities in shop floor management: A holistic approach to organisation at operational business levels in BPR projects
}

\author{
Eric Scherer \\ Institute of Industrial Engineering and Management BWI \\ Swiss Federal Institute of Technology ETH, 8028 Zürich, Switzerland \\ Martina Zölch \\ Work and Organisational Psychology Unit IfAP \\ Swiss Federal Institute of Technology ETH, 8092 Zürich, Switzerland
}

\begin{abstract}
Process orientation in production and business administration is a major means of increasing flexibility and speed while decreasing costs. During the past years the notion of human resources as a potential and means of ensuring flexibility in decentralised organisations gained importance. Even though systematic approaches to modelling and design of business processes and process organisation do exist, they mostly are related either to the derivation of targets on a strategic enterprise level or to specification of information technology and structures. Conversion of strategic targets into design of process activities at an operational level is usually not done in any systematic way and leaves a gap in existing methodology. This paper presents a human oriented approach to analysis and conceptual design of activities within a business process reengineering framework and its application to shop floor management.
\end{abstract}

\section{Keywords}

Business process reengineering, process organisation, task analysis, organisation development, human resources, participation, socio-technical system, shop floor management, manufacturing execution system

\section{INTRODUCTION}

Customer focus and strategic target orientation is a commonly recognised approach for business process reengineering (BPR). At the operational level of an enterprise it results in a complete change of organisation: tayloristic departments are replaced by target oriented teams. Each team 
is assigned specific tasks and performs a number of activities required to fulfil as part of processing an overall business process. To ensure a smooth processing, a well suited information and communication system is necessary. An information system provides all information necessary to perform a certain activity, supports the processing by supplying specific tools and controls the overall processing of tasks through a work flow system.

Several state-of-the-art integrated software systems provide these basic features and can be adapted to the demands of various industries and enterprises. This leads to a large variety of possible system layout and configuration based on one standard software. In production management and especially at operational level activities often are automated that previously were performed manually. In the shop floor domain this leads to a high tension between automation of technological activities and automation of business activities, i.e., the intersection of the physical and informational system (Scherer et al. 1994). Therefore system specification during the introduction of a new information system, leads to several problems on how to fit generic business processes into an existing shop floor environment.

\section{APPROACHES TO BUSINESS PROCESS DESIGN}

Business processes are information processes. They describe an informational or physical transformation and are performed by human resources or technological resources themselves. Time-based and target-oriented structuring of these processes leads to the formation of the overall process organisation (Picot \& Maier 1993, 11). Information technology thereby forms the back-bone of process organisation whereas human resources are a source of flexibility within the system, since by his intelligence a human can act independent and creative (Kosiol $1966,65)$. A human can provide flexible reactions and adapt his own work methodology if the overall system suffers situational disturbances (Mertins et al. 1992, 205), e.g., in case of urgent orders or a machine breakdown. Human resources therefore are of key value for an enterprise (Warnecke 1993, 58), not only as bearer of an enterprise's know-how and expertise, but as key to organisational flexibility. This aspect of human resource relation to process organisation is often ignored by BPR projects and by most technical-organisational innovation. This situation is enforced by the emphasis on a primarily technical top-down approach as proposed by American BPR exponents (e.g., Hammer \& Champy 1993) and leads to an theoretical system engineered on a flip chart rather than an organisation carefully developed (Osterloh \& Frost 1994). This presents a thinking similar to approaches common during the CIM euphoria of the 1980s which - by relying on a primarily technical design - mostly led to failure (Mandl 1993). Still newly designed activities within a business process framework form tasks that are to be performed by real people. BPR projects have to consider process organisation, information technology and human resources equally as potentials for design, and unify them in a holistic system.

\section{Formal methods for specification of business processes}

For design and specification of business processes several suitable methods and tools do exist (e.g., Scheer 1994, Curtis et al. 1992, Huckvale \& Ould 1993) and have been practically applied (e.g., Keller 1994). Usually activities are described and linked by discrete events. This forms the basic control view of the system model. Each activity is related to data and information necessary for execution. Additionally each activity is assigned its information resource, e.g., a 
computer or software system, and the affected organisational unit, e.g., departments or employees. Existing computer-aided tools and methods offer made easy support for formal process specification even at high complexity. No support is offered for the conceptual design of human resources, information technology and organisation itself (see Klein 1994). Accordingly information system design usually is carried out by experts, still human resource issues are often left to participatory approaches. Participation offers a significant contribution to project management techniques (Morris \& Brandon 1994, 213ff), leads to a multipersonal approach to problem-solving and helps to transform employees from being affected to being involved (Baitsch 1985). Participation still does not ensure that human potentials really are utilised within a reengineering project (Zölch 1992). Therefore it is necessary to develop and utilise methods that offer guidance and expertise to utilisation of human potentials.

\section{Principles for human-oriented conceptual design}

Each employee assumes a number of tasks, each task referring to the processing of a number of consecutive activities, i.e., a section of an overall business process. As part of his responsibilities an employee deals with activities of several business processes of different characteristics at the same time. The perception of a business process by a single employee presents the process as a limited number of activities he has to perform to fulfil the task assigned to him. The summation of all activities of the various processes forms the task environment an employees is assigned as part of his daily work, Figure 1 .

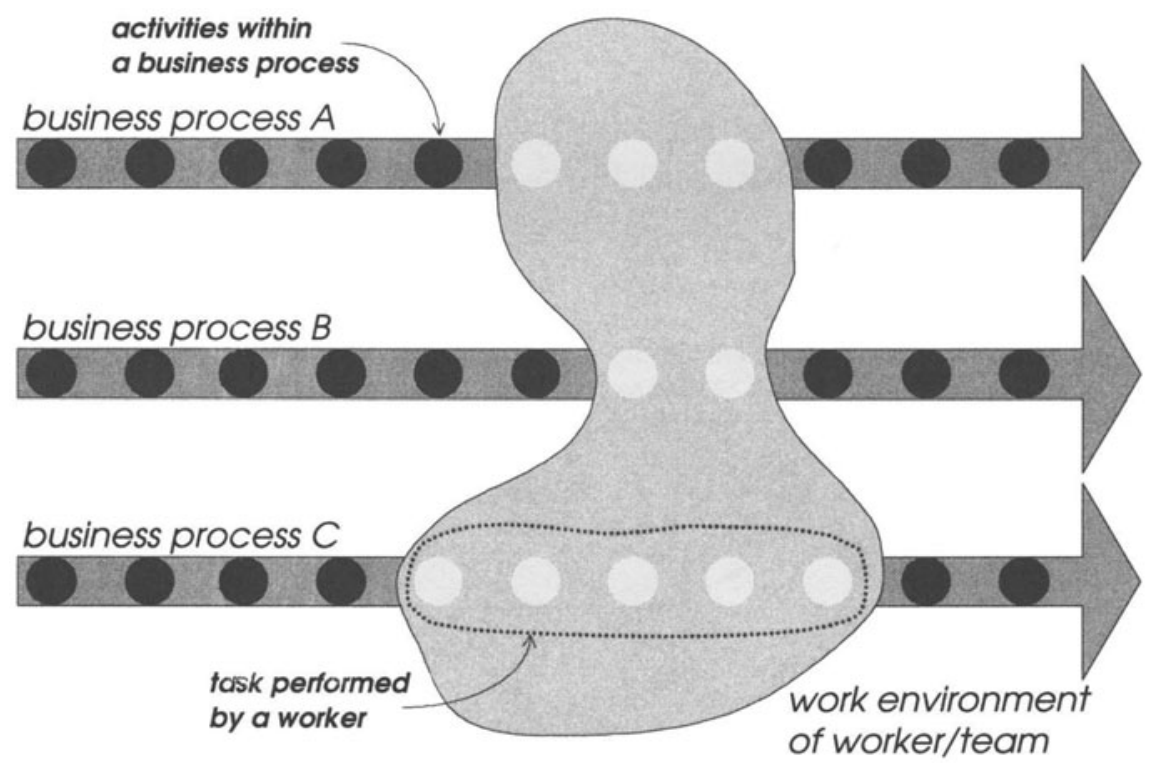

Figure 1 Process view vs. task view of activities. 
Ensuring a positive and demanding task environment for each employee makes it necessary to design tasks in a holistic and humane way. Design principles include completeness, variety and richness of meaning of tasks as well as possibilities for social interaction, autonomy, opportunity of learning and personal advancement, time independence and the opportunity of coping with demands without stress and hindrances while tasks are carried out (Ulich 1994, 161). Tasks designed according to these principles lead to an intrinsic motivation of employees and willingness to take responsibility, to gain knowledge through experience, stay mentally alert and develop self-esteem. This leads to a work-oriented perspective trying to utilise and advance human resources. Still complete informational support for all tasks has to be ensured and maintained, i.e., all information necessary has to be provided ergonomically and with easy access. Holistic design of tasks thereby gives access to human resource potentials within process-oriented organisations and helps to foster these potentials. This promotes the overall system performance in respect of flexibility, quality and economy.

Criteria based methods for system design offer a useful addition to BPR methodology and can provide a distinctive description of the informational and social realty of business processes. Work-psychological research has brought up a number of expertise based methodologies for analysis and assessment of tasks within administration and production management (Leitner et al. 1987 \& 1993, Volpert \& Oesterreich 1991, Dunckel et al. 1993, Weik et al. 1994). Assessment of tasks utilising conceptual criteria can offer advice to business process design at operational level. This leads to a combined top-down/bottom-up procedure within the BPR framework equally utilising human resources and information technology to achieve an ideal process organisation, Figure 2.

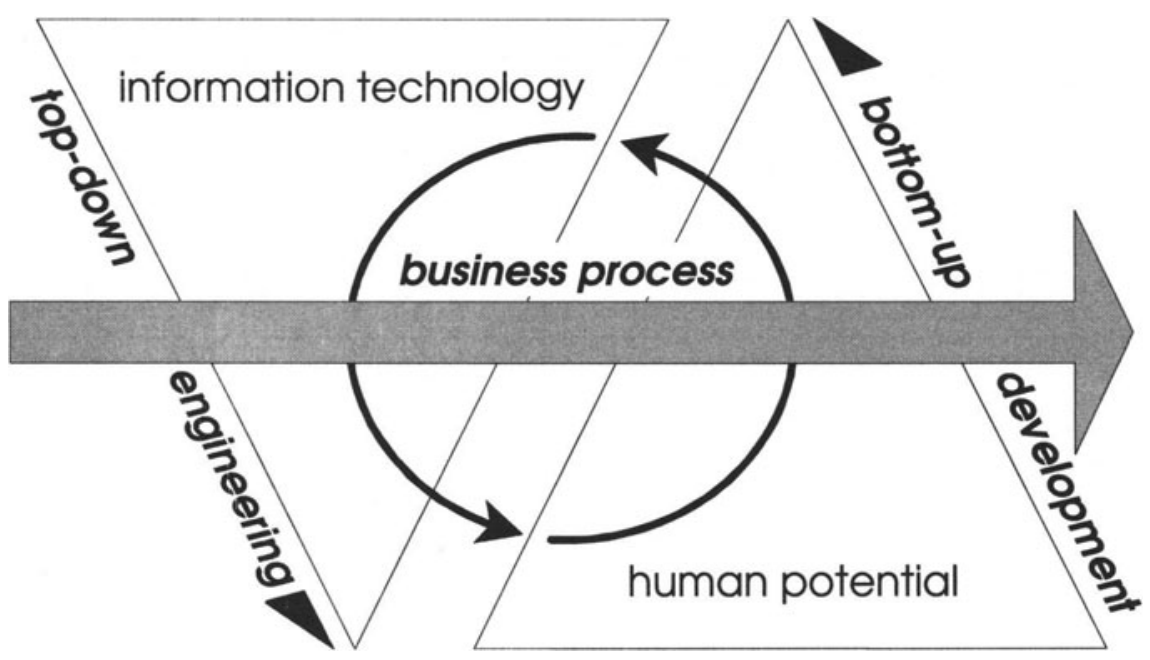

Figure 2 Top-down engineering and bottom-up development of process organisation 


\section{CRITERIA BASED TASK ANALYSIS AND DESIGN}

In the perception of work-psychological research, a task performed by an employee forms the nucleus of each socio-technical system (Ulich 1994, 157ff) and links individual and organisation (Volpert 1987, 14). Hence a task is not primarily perceived as function or duty to be fulfilled as part of a business process or a technical system but as a number of activities to be performed by an individual. The individual becomes an acting character and adopts certain objectives to lead his own action. A task's objective and the activities necessary to fulfil a task can be utilised to assess positive requirements toward the affected employee (Oesterreich \& Volpert 19986). This leads to equivalent advises for conceptual design.

\section{The KABA method}

The Contrastive Task Analysis and Design Method (KABA) is a procedure to analyse and assess work tasks in administration and offices and is originated by work psychologists (Dunckel 1989, Dunckel et al. 1993). It can be utilised to indicate possible consequences of new and existing information technology toward the employees. Originally designed for qualified work in industrial administration, banking, insurance and government, it presents itself useful for administrative tasks in production planning and management and therefore was adopted for use at operational levels within production.

It can be assumed that human acting is goal oriented, object related, social and flexible. Humans can adopt strategic goals as proposed by strategic management for their own acting, object related thinking easily reduces complexity and social behaviour leads to the ability to learn and advance. Based on these assumptions eight key criteria have been derived to assess the human potentials used at a certain system state. Tasks promoting human characteristics and potentials have to offer (1) a large scope of decision, (2) temporal scope, e.g., time independence, (3) transparency and the possibility to influence the conditions of work, (4) a variety of methods of working, and (5) the necessity to communicate. Additionally tasks should be (6) free of organisational or technical hindrances, offer (7) physical activity, and should be related to (8) material and social reality. This allows to compare the abilities of human resources in contrast to information technology.

KABA can be utilised during redesign of existing process organisation to identify new human oriented potentials in system design. Therefor existing tasks are recorded and the results of the assessment are used for basic requirement specification, e.g., in case of replacement of an old MRP II system. During conceptual design of a new process organisation, KABA offers foresighted assessment to various design variations and stages. This is useful to assess positive and negative effect of proposed software features or computer based communication systems, e.g., electronic mail or video conferencing. Eventually it achieves assessment of existing systems.

\section{Application of $K A B A$}

The KABA analysis is conditional, i.e., it does not assess the employees themselves and their individual evaluation of the situation but the tasks to be performed and their related work conditions. During analysis, the investigator (1) describes the set of task to be performed by each employee or each characteristical group of employees. The tasks can be derived based on a real system or a prospective one as achieved through a proposed business process layout. Each 
task is identified and distinguished toward others. Relevant information and control flow is recorded, i.e., how orders are submitted and which work flow information and triggers are used. Each task identified is (2) split up into the activities necessary to perform a task successfully. All required information and related documents, requirements to access information, processing time and utilised information technology resources are recorded. This step of KABA principally leads to a formal description of the control view similar as achieved through process modelling according to Scheer (1994). Based on the knowledge acquired, (3) the impact of information technology is assessed for each activity. Based on the previously listed key criteria it is checked whether the used or proposed information technology has a positive impact on the tasks, e.g., easy access to remote information, or negative, e.g., limitation of the scope of decisions. Based on the knowledge gained, (4) measurements for human oriented system design and utilisation of human potentials can be derived.

Practically KABA is lead by orientational questions allowing the investigator to examine the specific aspects of the work system. The examination leads to a classification according to several criteria and various stages that possibly can be achieved. Figure 3 gives an example of grading.

\begin{tabular}{l:l}
\hline Level I & Communication about deviation of determined actions \\
\hline Level $\mathbf{2}$ & Communication about how to determine a course of action \\
\hline Level 3 & Communication regarding consequences by determining a course of action \\
\hline Level 4 & Communication in regard to making one common decision \\
\hline Level 5 & Communication in regard to making several connected decisions \\
\hline Level 6 & Communication about common decisions in several spheres \\
\hline Level 7 & Communication in regard to development of new procedures \\
\hline
\end{tabular}

Figure 3 Levels for the criteria „Communication and cooperation requirements“

Based on this classification, KABA indicates necessary improvements and measures to access human potentials and permits benchmarking among different teams, organisation and enterprises. Based on job descriptions or similar documents, each level easily can be interpreted in correspondence to specific activities to be improved. By comparing an employee's qualification profile with the profile demanded to fulfil prospective tasks, measurements for personal advancement can be derived. This leads to a perception of tasks by employees not as stress but as challenge and guarantees positive incentives (Alioth 1980, 31).

\section{TASK DESIGN FOR SHOP FLOOR MANAGEMENT}

The tightening of the logistic supply chain in customer driven production enforces reduction of planning hierarchies and leaves the shop floor level of any production enterprise facing more and more challenges. Reality at the shop floor includes growing external demand, e.g., quality, quantities, variety and speed of products and orders, and internal, e.g., new technologies and 
complex product structure. These requirements are opposed by heterogeneity and uncertainty within the shop floor domain. Heterogeneity is caused through (1) technologically multifarious machines, (2) different type of production resources, (3) contradicting planning objectives, (4) different production strategies, e.g., KANBAN and make-to-order, (5) non-standardised external and interdepartmental interfaces, i.e., due date allowance, order/lot size, delivery procedures. Uncertainty is created through frequent changes of orders and unpredictable behaviour of the production system, e.g., machine breakdown or illness. Hence all resources for shop floor management, human resources, information technology and organisational structure have to be carefully utilised and designed toward a holistic system.

\section{Case study in electromechanical manufacturing}

To provide deeper insight, a short case study is given. At a Swiss manufacturer of optoelectronical instruments a concept for a new production order processing framework was developed and was to be implemented. This included establishing of a number of product oriented, market driven segments (cost centres) for assembly of final products and several technology-oriented, make-to-order segments for internal supply of parts and pre-assemblies. The processing of all orders on an aggregated level was supported by the introduction of a new MRP II software package. This was to release aggregated production orders, issue routings and control workflow between the segments. Within the electromechanical manufacturing segment this led to the decision to introduce a new computer aided manufacturing execution system (MES), or „Leitstand“, to replace the previously manual system. Through the MES overall performance should be increased and requirements met as set within the new production order processing framework. Project objectives included among others (1) creation of simple and flexible business processes, (2) creation of more autonomy for operators, (3) increase of reactivity upon work load changes, (4) increase of situational transparency, and (5) humanisation of the work environment. Table 1 gives characteristic numbers for the concerned shop floor segment.

Table 1 Characteristic numbers

\begin{tabular}{lr}
\hline Staff & 44 person \\
\hline Number of active product types & 110 \\
\hline Number of active assembly types & 790 \\
\hline Number of used parts per year & 11 million \\
\hline Number of orders per year (MTO \& KANBAN) & 6.000 \\
\hline Percentage of KANBAN orders & $35 \%$ \\
\hline Average lot size & 60 \\
\hline Average lead time (production) & 8 days \\
\hline Average lead time (supply) & 50 days \\
\hline Queuing time/production time & $60 / 40$ \\
\hline
\end{tabular}


Analysis included (1) description of order related business processes at the operational level and within the overall order processing framework, (2) task analysis and definition of human resource requirements, and (3) analysis of information system capabilities (also see Bullinger \& Hirsch 1994, 20ff). For analysis and design the ARIS methodology (Scheer 1994) was chosen as formal modelling technique, but the KABA methods were utilised for conceptual design of processes and to contrast human potentials and MES functionality. During analysis four classes of employees were investigated at their work place: floor supervisor, foreperson, skilled and unskilled workers. Figure 4 gives an example of the results of the task analysis in case of skilled and unskilled workers. The reference indicated is based on work psychological research and gives a benchmark for a realistic workplace classified humane.

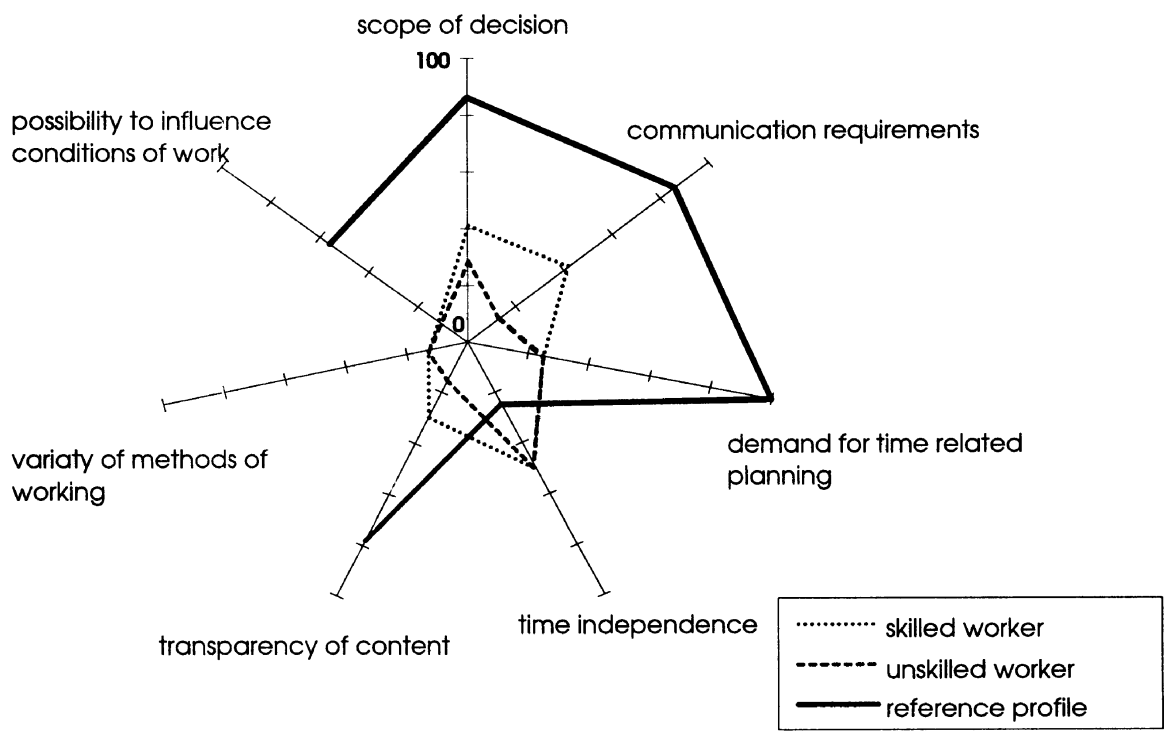

Figure 4 Analysis results for skilled and unskilled workers

\section{Results and measures}

Analysis led to following diagnosis: (1) several information is not easy to access or is missing, (2) division of planning and execution of activities causes loss of information and unnecessary interfaces, (3) lack of work-related communication causes loss of knowledge, i.e., only communication on what to do and not how to do it. This resulted in redesign of order processing and related tasks in many respects. Prime measure was a reduction of hierarchies to two levels. Supervisor and foreperson were combined into the role "floor controller“, all workers formed teams of 10-12 people. Key task within each group was the distribution and assignement of jobs. In the old procedure each job was split up according to its routing and assigned the relevant machines. In contrast, with the new procedure jobs are assigned to the workers themselves. This was possible since there was no specific domination of machines as 
restricting resource. Distribution of jobs through staff assignment is done in daily meetings and encourages a more object related perception by the workers. Figure 5 indicates the minimisation of hierarchies.

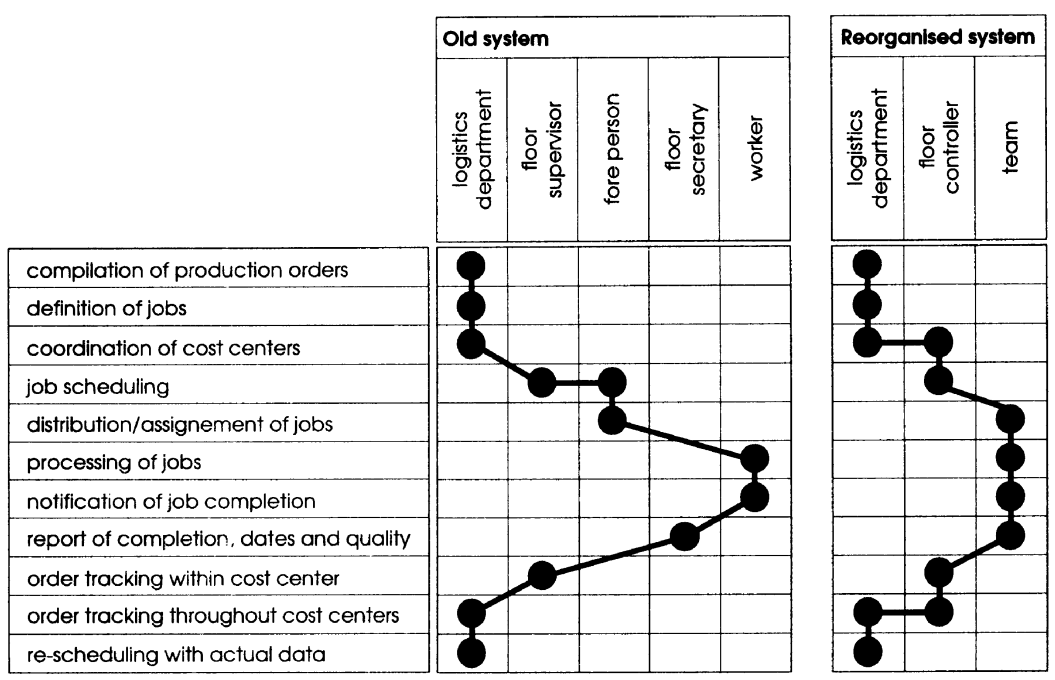

Figure 5 Allocation of shop floor management related tasks

To support staff assignment as key task, MES functionality was slightly adapted to treat human resources as key capacities in scheduling and present them in the GANTT chart. Further contrastive analysis of human and information technology potentials led to the definition of MES functions to be utilised, Figure 6. Through the MES and the allocation of job assignements within the teams it is possible to reduce proactive planning and scheduling tasks for the shop floor controller. This offeres more spare time for further management tasks and coordination with related segments. Reactive scheduling was improved through additional information provided by the system.

\section{$5 \quad$ REFLECTION}

Several approaches to restructuring organisation describe an enterprise as organism and propose the formation of decentralised and partially autonomous segments such as teams as a major means to increase productivity (e.g., Warnecke 1993). Thinking in processes and customer focus establishes a strategic guideline for straight forward reengineering of organisational units at an operational level like the shop floor. Modern information technology thereby offers an extensive potential to support business processes (Frese 1994, 133). Information technology provides information necessary to perform activities successfully and supports and controls the overall work flow. Distributed systems enable co-operation and communication among different 


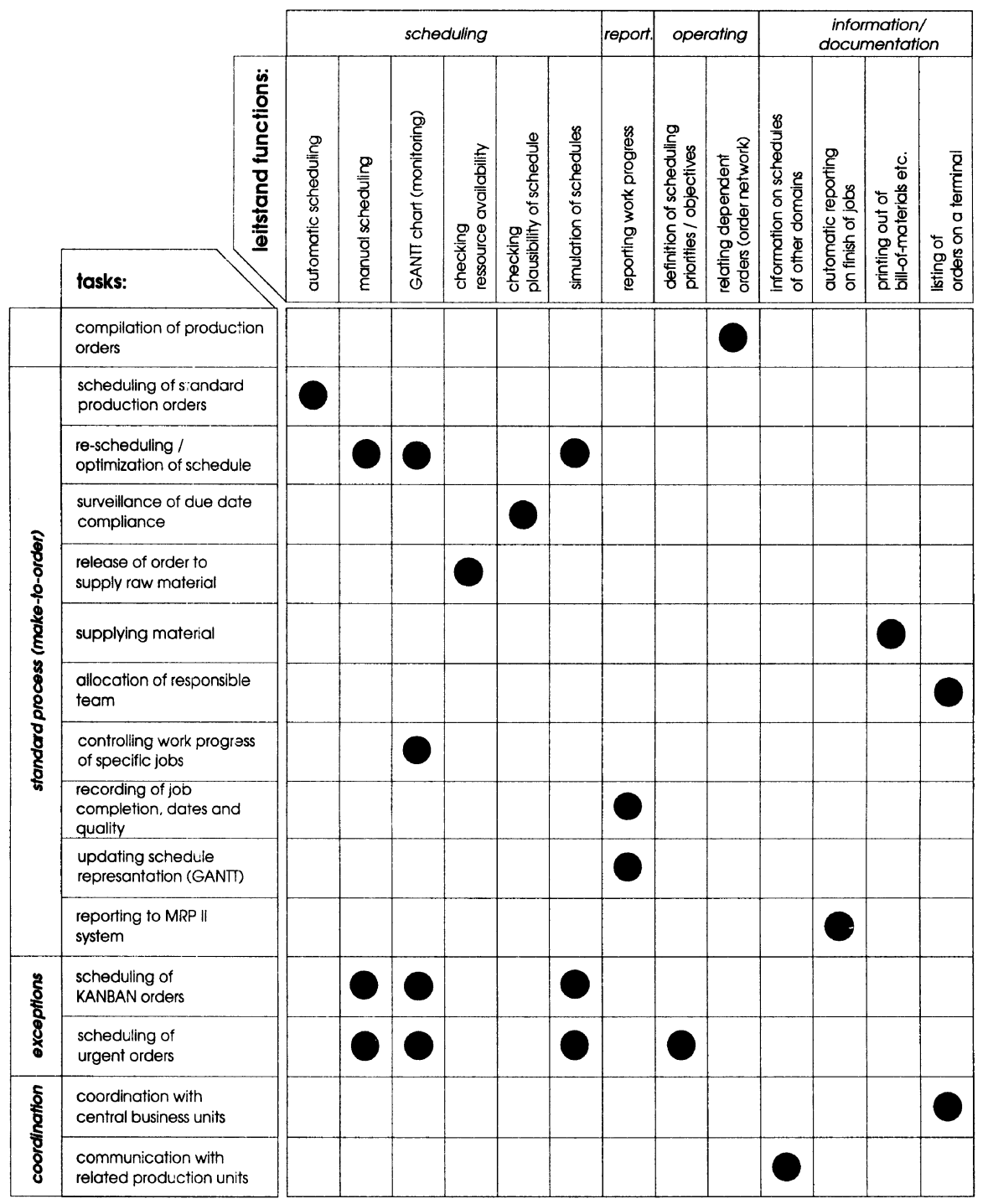

Figure 6 MES functions and supported tasks 
business segments, teams and distributed production sites without the necessity of direct and personal contact. It is possible to obtain information previously difficult to access and utilise it to make proactive decisions and decisions based on broader knowledge. Information technology seemingly offers a broad variety of design possibilities. Simultaneously it leads to the danger of unnecessary and inefficient automation. At decision-making and execution of single process activities it therefore still necessary to consider individual intelligence only provided by human resources within the overall system.

Strategic decisions to reengineer an enterprise's organisation, e.g., flattening of hierarchies, establishing customer-oriented business segments or introducing a distributed production management software, always have to consider potentials and limitations at the operational level. In case of shop floor management BPR has to be supported by adequate and realistic task design considering individual qualification. It also has to consider the basic conflict between physical and informational tasks as performed by most employees at a operational business level such as the shop floor level. Therefore human resources and information technology equally have to be treated with expertise and conceptual methodology to form a holistic system. This does imply that a technologically feasible solution is not necessarily the solution required for positive system performance (Kötter \& Volpert 1993, 131). Contrastive analysis and design of tasks like KABA makes it is possible to design tasks and related activities within a distributed business process framework with a human resource perspective, and thereby utilises their potentials. To ensure lasting efficiency of the newly realised organisation permanent organisation development is necessary. Therefore employees have to have the opportunity to reflect their behaviour and performance as teams and individual and adopt personal goals for their work. This includes the possibility to question tasks and regulations set and change them adequately (see Marks 1991). The ability to reflect processes and organisation from the local perspective of the shop floor level ensures permanent improvement and flexibility within the process framework for production management.

\section{REFERENCES}

Alioth, A. (1980): Entwicklung und Einführung alternativer Arbeitsformen. Huber, Bern.

Baitsch, C. (1985): Kompetenzentwicklung und partizipative Arbeitsgestaltung. Frankfurt a. M.

Bullinger, H.-J., Hirsch, B. E. (eds.) (1994): Leitstände für die Werkstattsteuerung. Schriftenreihe der Bundesanstalt für Arbeitsschutz, Fb 705. Wirtschaftsverlag NW, Bremerhaven.

Curtis, B., Kellner, M. I., Over, J. (1992): Process Modelling. Communications of the ACM 35 (1992) 9, 75-90.

Dunckel, H. (1989): Contrastive task analysis, in: Landau, K., Rohmert, W. (eds.): Recent developments in job analysis. Taylor \& Francis, London, 125-136

Dunckel, H., Volpert, W., Zölch, M. et al. (1993): Kontrastive Aufgabenanalyse im Büro - Der KABA Leitfaden, Grundlagen, Manual, Arbeitsblätter. vdf/Teubner, Zürich/Stuttgart.

Frese, E. (1994): Aktuelle Organisationskonzepte und Informationstechnologie. Management \& Computer 2 (1994) 2, 129-134.

Hammer, M., Champy, J. (1994): Reengineering the corporation. paperback edition, HarperBusiness, New York.

Huckvale, T., Ould, M. (1993): Process Modelling: Why, What and How, in: Spurr, K., Layzell, P., Jennison, L., Richards, N. (eds.): Software Assistance for Business Re-engineering. John Wiley, Chichester et al., 81-97. 
Keller, G. (1994): SAP Business Workflow Management - Durchgängige Geschäftsprozessoptimierung mit Hilfe des R/3-Systems, in: Scheer, A.-W. (eds.): 15. Saarbrücker Arbeitstagung 1994 Rechnungswesen und EDV. Physica, Heidelberg, 471-495.

Klein, M. M. (1994): Reengineering Methodologies and tools. Information Systems Management 11 (1994) 1, 30-35.

Kosiol, E. (1966): Die Unternenhmung als wirtschaftliches Aktionszentrum. Rowolth, Reinbek bei Hamburg.

Kötter, W., Volpert, W. (1993): Arbeitsgestaltung als Arbeitsaufgabe - ein arbeitspsychologischer Beitrag zu einer Theorie der Gestaltung von Arbeit und Technik. Zeitschrift für Arbeitswisenschaft 47 (1993) 3, 129 -140.

Leitner, K., Volpert, W., Greiner, B., Weber, W., Hennes, K. (1987): Analyse psychischer Belastung in der Arbeit: Das RHIA-Verfahren, Handbuch und Manual. Verlag TüV Rheinland, Köln.

Leitner, K., Lüders, E., Greiner, B. Ducki, A., Niedermeier, R., Volpert, W. (1993): Analyse psychischer Anforderungen und Belastungen in der Büroarbeit: Das RHIA/VERA-Büro-Verfahren, Handbuch und Manual. Hogrefe, Göttingen.

Mandl, C. (1993): Computerintegrationsprojekte - Die Logik des Misslinges. IO Management 63 (1993) $12,54-58$.

Marks, S. (1991): Gemeinsame Gestaltung von Technik und Organisation in soziotechnischen kybernetischen Systemen. VDI Verlag, Düsseldorf.

Mertins, K., Albrecht, R., Steinberger, V. (1992): Werkstattsteuerung - Werkstattmanagement. Hanser, München.

Morris, D. C., Brandon, J. (1994): Re-engineering your business. paperback edition, McGraw-Hill, New York et. al.

Oesterreich, R., Volpert, W. (1986): Task analysis for work design on the basis of action regulation theory. Economic and Industrial Democracy 7 (1986) 4, 503-527.

Osterloh, M., Frost, J. (1994): Business Reengineering - Modeerscheinung oder Business Revolution? ZfO 63 (1994) 6, 356-363.

Picot, A., Maier, M. (1993): Interpendenzen zwischen betriebswirtschaftlichen Organisationsmodellen und Informationsmodellen. Information Management 8 (1993) 3, 6-15.

Scheer, A.-W. (1994): Business process engineering: Reference models for industrial enterprises. Springer, Berlin et al.

Scherer, E., Rössle, R., M. Zölch (1994): Ganzheitliche Gestaltung der Werkstattsteuerung. IO Management 63 (1994) 3, 59-63.

Ulich, E. (1994): Arbeitspsychologie. 3. Aufl., vdf/Poeschel, Zürich/Stuttgart 1994.

Volpert, W. (1987): Psychische Regulation von Arbeitstätigkeiten. in: Kleinbeck, U., Rutenfranz, R. (eds.): Arbeitspsychologie. Horgrefe, Göttingen, 1-42.

Volpert, W., Oesterreich, R. (eds.) (1991): VERA Version 2: Arbeitsanalyseverfahren zur Ermittlung von Plarungs- und Denkanforderungen. Handbuch und Manual. Technische Universität Berlin 1991.

Warnecke, H.-J. (1993): Revolution der Unternehmenskultur - Das Fraktale Unternehmen. 2. Aufl., Springer, Berlin et al. 1993.

Weik, S., Grote, G., Zölch, M. (1994): KOMPASS - Complementary analysis and design of production tasks in sociotechnical systems, in: Kidd, P.T., Karwowski, W. (eds.): Advances in agile manufacturing. IOS Press, Amsterdam.

Zölch, M. (1992): Partizipation contra kriteriengeleitete Augabenbewertung - eine Scheinalternative, in: Langenheder, W., Müller, G., Schinzel, B. (eds.): Informatik cui bono? Springer, Berlin et al., 243-24T. 